Editorial

\title{
The City of Digital Social Innovators
}

\author{
Chiara Certomà ${ }^{1,2, *}$, Mark Dyer ${ }^{3}$ and Antonella Passani ${ }^{4}$ \\ ${ }^{1}$ ESOMAS, University of Turin, 10124 Turin, Italy; E-Mail: c.certoma@sssup.it \\ 2 Center for Sustainable Development, Ghent University, 9000 Ghent, Belgium \\ ${ }^{3}$ School of Engineering, University of Waikato, 3216, Hamilton, New Zealand; E-Mail: mark.dyer@waikato.ac.nz \\ 4 T6 Ecosystems srl, 00187 Rome, Italy; E-Mail: a.passani@t-6.it \\ * Corresponding author
}

Submitted: 1 October 2020 | Published: 14 October 2020

\begin{abstract}
The concept of digital social innovation (DSI) refers to a fast-growing set of initiatives aimed at providing innovative solutions to social problems and needs by deploying the potential of the social web and digital media. Despite having been often interpreted as synonymous with digitally enhanced social innovation, we explain here why, in consideration of its epistemological and socio-political potentialities, we understand it as an interdisciplinary set of practices able to interpret and support the changes of a society that is more and more intrinsically virtual and physical at the same time. Notably, we briefly discuss how DSI processes can be functionally mobilized in support of different socio-political projects, ranging from the mainstream neoliberal to the revolutionary ones. Eventually, we provide a synopsis of the articles included in this thematic issue, by aggregating them accordingly to the main stakeholders promoting the DSI projects, being more bottom-up oriented or more institutional-based.
\end{abstract}

\section{Keywords}

digital social innovation; digital turn; urban governance; urban planning

\section{Issue}

This article is part of the issue "The City of Digital Social Innovators" edited by Chiara Certomà (Ghent University, Belgium), Antonella Passani (T6-Ecosystems, Italy) and Mark Dyer (University of Waikato, New Zealand).

(C) 2020 by the authors; licensee Cogitatio (Lisbon, Portugal). This article is licensed under a Creative Commons Attribution 4.0 International License (CC BY).

\section{Introduction}

Social innovation has always had a crucial role in promoting progressive development in society (Busacca, 2013; Moulaert, MacCallum, Mehmood, \& Hamdouch, 2013). With the advent of the digital age and the transition of a large part of our social lives (and private lives) to the internet, the space for social agency has expanded well beyond the physical domain (Ash, Kitchin, \& Leszczynski, 2018; Castells, 1996; de Cindio \& Aurigi, 2008). Today, it is widely recognised that the digital revolution offers new opportunities for the social agency to operate innovative interventions, notably concerning the structure and functioning of contemporary cities (Gairola \& Roth, 2019; Graham, Zook, \& Boulton, 2013). At the same time, it opens up new challenges such as misinformation (Flynn, Nyhan, \& Reifler, 2017) and digital divide among different social groups and among territories which add to already existing disparities (Mossberger, Tolbert, \& McNeal, 2007). By stepping beyond the acritical technology-optimism of the smart innovation perspective (Aitamurto, 2012; Prahalad \& Ramaswamy, 2004) and buying into some of the radical analysis of digital capitalist discontents (Lanier, 2006; Herzog \& Hartwig, 2008), contributions collected in this thematic issue explore how traditional planning and governance processes are challenged by the agency of digital social innovators.

It is increasingly evident that the movement of digital innovators, hackers, makers, social entrepreneurs, open access promoters, and cyber activists is advancing new ways of organising and equipping the city to im- 
prove people's livelihood and liveability in terms of education and job, political participation, science and technology, economy and business, housing, public space design, and public services provision (Caulier-Grice, Davies, Patrick, \& Norman, 2012; Dyer et al., 2019). The mushrooming of innovative solutions to social problems bootstrapped by the advent of the social web and digital media (Bria, 2015) provides new opportunities for direct participation practices emerging in different segments of the European societies. However, opportunities are not necessarily balanced or equal. On the one hand, participative approaches are increasingly seen as a condition for promoting democracy, able to guarantee fairer access to goods and opportunities, and associated with ideals of accessibility, transparency, and engagement (Dyer, Gleeson, Ögmundadottir, Ballantyne, \& Bolving, 2017; Gleeson, Dyer, \& Grey, 2017). Yet, on the other hand, the diffusion of these very practices is not homogeneous among countries and regions and their capability of scaling up from pilot experiences to systematic changes is still under investigation (Moore, Riddell, \& Vocisano, 2015; Westley, Antadze, Riddell, Robinson, \& Geobey, 2014).

\section{Different Approaches to Digital Social Innovation}

Traditional research on social innovation has hardly acknowledged that the digital turn, further than equipping existing processes with more robust communication and organisational tools, radically transforms the socially constructed nature of tackled problems, the choice of which problems are worthy of support, the construction of knowledge about them, and their ethical impacts (Lawrence, Dover, \& Gallagher, 2014). While digital social innovation (DSI) has been, in fact, initially regarded as a form of social innovation triggered, empowered, mediated, or even transformed by the use of digital technologies (Boelman \& Heales, 2015; Howaldt \& Schwarz, 2016; Millard \& Carpenter, 2014; TEPSIE, 2014), we claim it is something more. DSI is, actually, producing epistemological (i.e., how people come to define, know, and operate on reality) and political changes (i.e., how people modify the meaning, forms, and ends of governance processes) that call for a critical approach to interpret the transformations of both society and technology landscape. Therefore, in this thematic issue, we do not refer to DSI as synonymous with digitally enhanced social innovation (which is, of course, a desirable and relevant part of the phenomenon); we rather prefer to see it as an interdisciplinary set of practices able to interpret and support the changes of a society which is more and more intrinsically virtual and physical at the same time.

Such a vision is well illustrated by many of the projects financed by the European Commission under the Collective Awareness Platforms for Sustainability and Social Innovation (CAPS) program. CAPS' definition has been introduced in 2012, in the context of the Seventh Framework Programme of research, to identify an emer- gent group of projects and, to a certain extent, a new research area (Passani, Spagnoli, Bellini, Prampolini, \& Firus, 2015). Indeed, "Collaborative Awareness Platforms can be seen as ICT-supported collaborations of human and non-human actors which enable and facilitate the production, sharing and sense-making of information gathered through citizen engagement and through sensors and the like" (Arniani et al., 2014). Key aspects of the projects financed in that domain have been the strong engagement of citizens, the focus on pressing social or environmental issues, and a strong interdisciplinary effort. It is not by chance that some of the projects that concurred to the emergence of the term DSI have been financed by this program. Hence, we prefer the term DSI to others such as 'tech for social good' and 'civic tech' because it can really put the social and the technical dimensions of innovation on the same level, and it can call for a truly interdisciplinary and citizen-centred way of addressing societal issues.

Of course, it is also important to acknowledge that there are different forms of DSI, ranging from those functional to the reproduction of the status quo to those subverting it-including a vast array of nuances in between (Maglavera, Niavis, Moutsinas, Passani, \& De Rosa, 2019). We find DSI initiatives intended to make existing socio-political and economic processes faster, more efficient, or effective without inducing any change in the structure of society or in its understanding. Smoothly integrated into the smart city rationality, these initiatives are often supported or, sometimes, co-opted by the neo-liberal institutions (e.g., Microsoft Civic Tech; Spicknall, 2018). A slightly more inclusive, participatory, and people-friendly approach characterizes DSI initiatives advanced by CSOs and public administrations and promotes the establishment of collaborative platforming and bring citizens to cooperate with institutions (e.g., Nesta, 2020). Proceeding along an imaginary line between mainstream and revolutionary processes, we can identify a reformist approach in DSI projects that aim at directly intervening and transforming the urban sociospatial structure and its functioning by deploying the potential of existing digital technologies and leveraging on their co-creative and pervasive potentiality (Certomà, Rizzi, \& Corsini, 2015). These include, for instance, initiatives aimed at making migrant people emerging from invisibility by learning the local language (e.g., Speak, 2020) and providing mutual aid (e.g., Mosquera, 2020). While some of them use proprietorial technologies (e.g., Fixmystreet, 2020), other couple their social commitment with concerns for the ethical software development and adopt open access and open source technologies (e.g., Smart Citizen Kit; Smart Citizen, 2020). Eventually, we identify DSI initiatives advanced by cyberactivists, hackers, and makers with the explicit intention to revolutionising technology rules and tools. In so doing, they move the social struggle in the digital space battleground. They fight to promote people's digital sovereignty over their data (e.g., Lleialtat, 2020), access 
to the web through community-owned network infrastructures (e.g., Guifi, 2020; Ind.ie, 2020), and the possibility for self-fabrications of technological tools (e.g., Arduino, 2020). By following up one of the key intuitions of the fathers of digital revolutions-i.e., that we can only change society by changing the tools it uses (Cadwalladr, 2013)-revolutionary DSI initiatives invent, hack, boycott, and transform the technologies of everyday life, to contrast the massive fluxes of the economic, financial, material, and symbolic power of digital capitalism (Coleman, 2015; Zuboff, 2019). Critical scholars and internet activists involved in revolutionary DSI initiatives raise doubts about the potentialities of DSI to foster real participation in governance and to serve public good because these contain "both utopian and dystopian possibilities for new forms of sovereignty" (Thompson, 2018 , p. 1178). Main criticalities resided in the transformation of participation meaning and practices (Baccarne, Mechant, Schuurman, Colpaert, \& De Marez, 2014); the capability and possibility to govern DSI in the emergent public-private governance regimes; and the changes in power geometries and empowerment mechanisms induced by the digital turn (Bendiek, Godehardt, \& Shulze, 2019; Parayil, 2005).

\section{Synopsis of the Thematic Issue}

The collection of articles presented in this thematic issue provides an intriguing spectrum of perspectives about the emergence of DSI as either a top-down driven or a grassroots bottom-up initiative located in cities or rural villages across Europe, China, and New Zealand. In many cases, authors highlighted a surprising lack of scientific evidence about how DSI functions in practice and how the different actors learn from the experience so that the lessons learnt can promote reflection, rethinking, or even transformation of status quo at a time of significant change.

The article by Certomà (2020) presents and discusses the thematic issue's topic. It points out that spacerelated aspects have been incidentally addressed by innovation management and regional studies researches. In contrast, a critical geography approach could help refining the analysis of the urban space as a physical space augmented by digital connections. Interestingly, it could also reveal to what extent contemporary cities are merely working as laboratories for experimenting market-led technocratic solutions or as incubators of citizens' critical engagement. As such, critical geography helps unveiling how DSI initiatives are produced and mobilised in the society, along with discourses and imaginaries about technological development.

In turn, the studies by Dyer, Weng, Wu, Ferrari, and Dyer (2020), Leyshon and Rogers (2020), and Grossberndt et al. (2020) investigate how digital technologies can make it possible for citizens to expand their space of action in the city, by designing and realising much-needed autonomous initiatives.
In particular, the article by Dyer et al. (2020) describes how a new, in-house developed digital platform entitled 'Urban Narrative' uses computational linguistic tool FLAX to extract shared dialogue and stories from public engagement exercise initiated by the city of Christchurch, New Zealand, called 'Share and Idea,' following the 2010 and 2011 earthquakes. Using collocation methodology, the technique illustrated how the public's interests in key features about the city's soft and hard infrastructures could be readily identified and compiled to give an overall perspective about priorities for the future development of a city. The grassroots outputs from the public engagement exercises were compared with top-down governmental statistical data to either show agreement or disagreement on topical issues such as provisions of affordable public transport or security measures for street safety. Furthermore, the article drew intriguing parallels between processes involved in well organised public participation and the participatory design itself, both of which are needed for codesign or co-development of sustainable communities and cities.

In the case of Leyshon and Rogers (2020), a novel digital platform called CJNN aided online journalism to emerge in the community. The pilot study involved four local communities in Cornwall, UK. The intention was to produce a sense of place through sharing stories and images that reflect the lived realities of people's lives. The most relevant collaborative journalistic effort was a story cluster that produced mass collaboration about an unusual weather event that affected the entire geographic area of Cornwall. Ultimately, the research pointed out how digital technologies-aided socially innovative processes can support marginalised groups whose voices are often absent in the mass media.

The theme of grassroots engagement continues in the article by Grossberndt et al. (2020), who reported on results from a digital platform that enabled the public to record their perceptions of poor air quality in greater Oslo, Norway, and compare them with results from official measurements of pollution (PM10, PM2.5). This was undertaken using the digital platform cityAir and hackAIR. Although not intended to be directly correlated with measured values of air quality, the results show a reasonable agreement that confirmed expectations that air quality was poorest near road networks and especially in central Oslo. Quite rightly, the authors highlighted the opportunity these digital platforms provided to raise air quality awareness within the city and its surrounding suburbs. The results also raise questions about what you do with the results when it becomes very clear that the air quality in certain parts of cities is unacceptably poor.

In comparison with these grassroots initiatives, the results from two top-down institutional case studiesDevlin (2020) and Bolli's (2020)-discuss the political rationalities underlying the development and introduction of digitally-aided collaboration contexts. 
The article by Devlin (2020) described early results from the introduction of a new urban planning and technology platform, \#PlanTech, in the UK, funded by the central government 'Connected Places Catapult.' Specifically, the article reports on the results of an ethnographic study of planning functions for Coventry City Council. Most of the ethnographic study describes the challenge of selecting an appropriate software vendor in a highly competitive market. At this stage in the project, it was too difficult to draw firm conclusions about the success or otherwise of the initiative. However, it was interesting to note that one of the drivers for the project was political frustration at the perceived inability of existing planning processes to promptly deliver new urban developments to help stimulate the UK economy.

In comparison, Bolli (2020) focussed on the emergence of makerspaces in China as an example of the integration of top-down and bottom-up dynamics which were characterized as ephemeral spaces for innovators, hackers, makers, and entrepreneurs shaped by a cultural context. The first makerspaces reportedly opened in Shanghai and Shenzhen in 2010 and attracted the attention of the Chinese government, who in 2015 published an initiative that subsequently influenced the typology of makerspaces in China. As such, the Chinese government supported a more entrepreneur and business culture over self-development and tinkering. Makerspaces were seen as an opportunity to shift the image of China from a world manufacturer with the label 'made in China' to a nation of innovation with the motto 'designed and created in China.' As a result, the Chinese government's initiative reportedly reduced the number of makerspaces as it has transformed the idea of makerspaces into entrepreneurship. Even so, makerspaces are seen as having multiple, potentially dissonant, roles in the Chinese context, namely fulfilling the ideology of the urban China dream, participating in the growing sharing economy and platformisation of the Chinese society.

Middle-out collaboration patterns emerging from public institutions and citizens networking in DSI initiatives are explored in the last set of articles by Zerrer and Sept (2020) and Ersoy and van Bueren (2020).

Although the majority of articles discussed DSI in an urban setting, the article by Zerrer and Sept (2020) describes DSI in a rural setting in two villages in Germany and discusses the integration of top-down and bottomup efforts. The case studies compared the emergence of DSI from a grassroots level in the village of Wokisrab compared to a top-down initiative in the village of Wesedun. The ethnographic study showed that in the case of Wokisrab, rural DSI was triggered by the arrival of a multiuse space with the only public Wi-Fi hotspot. The new activism led to a number of analogue social innovations before triggering engagement with regional competition that led to a new village strategy focusing on opportunities for digitalization, particularly on a digital communication platform and a shared village database. In comparison, Wesedun's journey towards rural DSI originated with participation in the Digital Countryside project co-funded by the European Union. The eventual DC project was managed by the Economic Development Corporation of the District. Wesedun realized five ideas were divided into two sections: demography, with the highest priority, and digital infrastructure. In order to meet the challenges of demographic change, the focus was to improve the quality of life, mobility, social integration, and autonomy of elderly villagers, for example through the village's internet courses, regularly fully booked. In each case, the study characterized the development of rural DSI by so-called 'smart villagers' as either a bottom-up process with outside support in the case of Wokisrab or as a top-down bottom-up-interplay in the case of Wesedun. For both villages, different types of actors were involved in the process of DSI. On a vertical level, top-down actors typically comprised professionals from outside of the village, where as bottom-up actors involved volunteers, belonging to the village. On the whole, the study identified three main groups of actors to create DSI: drivers, supporters, and users.

The role of actors for DSI was also seen as an important theme in the article written by Ersoy and van Bueren (2020), which reported on the creation of three 'temporary' urban living labs (ULL) following the global financial crash of 2008. Located in post-industrial shipping yards on the outskirts of Amsterdam, the alternative schemes based at Buiksloterham (De Ceuvel, Schoonschip, New Energy Docks) were intended to be temporary (10 years). However, during the trial process, the local communities became concerned that traditional developments would be resumed once the crisis passed. Hence, in April 2015, a Manifesto Circular Buiksloterham was signed by 20 professional private and public stakeholders for the so called 'City Lab Buiksloterham.' The article investigates how different actors learnt from the ULL experience in terms of learning theories where single, double, and triple loop learnings processes led to increasingly deeper and transformational learning experiences. Yet, in practice, the replication of innovation was found to be problematic because learning theories are more concerned with the learning setting, whereas in ULLS actors learn within a particular context. Interestingly, knowledge institutes, consultants, and the local water company were found to play a key role disseminating lessons learnt to other places within Amsterdam and beyond. Likewise, the establishment of Manifesto/Living Lab Circular Buiksloterham provided the framework for City Lab to exchange experiences with similar 'bottomup' initiatives in other cities.

In summary, the thematic issue provides a further contribution to the body of literature. It explores the different socio-political perspectives, participating actors, and governance processes activated by a broad range of existing DSI initiatives for appreciating the implications of the emerging socio-technological transformation in cities and regions. 


\section{Conflict of Interests}

The authors declare no conflict of interests.

\section{References}

Aitamurto, T. (2012). Crowdsourcing for democracy: A new era in policy-making. Helsinki: Committee for the Future. Retrieved from https://cddrl.fsi. stanford.edu/publications/crowdsourcing_for democracy_new_era_in_policymaking

Arduino. (2020). Homepage. Arduino. Retrieved at https://www.arduino.cc

Arniani, M., Badii, A., De Liddo, A., Georgi, S., Passani, A., Piccolo, L. S. G., \& Teli, M. (2014). Collective awareness platform for sustainability and social innovation: An introduction. Brussels: European Commission. Retrieved from http://www.transitsocialinnovation.eu/ content/original/Book\%20covers/Local\%20PDFs/ 140\%20Collective\%20awareness\%20platoforms\% 20for\%20sustainability\%20and\%20SI\%20in\% 20introduction\%20\%202014.pdf

Ash, J., Kitchin, R., \& Leszczynski, A. (2018). Digital turn, digital geographies? Progress in Human Geography, 42(1), 25-43.

Baccarne, B., Mechant, P., Schuurman, D., Colpaert, P., \& De Marez, L. (2014). Urban socio-technical innovations with and by citizens. Interdisciplinary Studies Journal, 3(4), 143-156.

Bendiek, A., Godehardt, N., \& Shulze, D. (2019). The age of digital geopolitics: Europe may well become the scene of a technological proxy war between the US and China. International Politics and Society. Retrieved from https://www.ips-journal.eu/in-focus/ chinas-new-power/article/show/the-age-of-digitalgeopolitics-3593

Boelman, V., \& Heales, C. (2015). Social innovation strategies: Regional report. Brussels: European Commission.

Bolli, M. (2020). Innovators in urban China: Makerspaces and marginality with impact. Urban Planning, 5(4), 68-77.

Bria, F. (2015). Growing a digital social innovation ecosystem for Europe: DSI final report for European Commission. London: NESTA. Retrieved from https://ec.europa.eu/futurium/en/system/files/ ged/50-nesta-dsireport-growing_a_digital_social_ innovation_ecosystem_for_europe.pdf

Busacca, M. (2013). Oltre la retorica della social innovation [Beyond the retoric of social innovation]. $\mathrm{Im}$ presa Sociale, 2, 39-55.

Cadwalladr, C. (2013). Stewart Brand's Whole Earth Catalog, the book that changed the world. The Guardian. Retrieved from https://www.theguardian.com/ books/2013/may/05/stewart-brand-whole-earthcatalog

Castells, M. (1996). The information age: Economy, society and culture (Vol. I). Oxford and Cambridge, MA: Blackwell.
Caulier-Grice, J., Davies, A., Patrick, R., \& Norman, W. (2012). Social innovation practices and trends. Brussels: European Commission.

Certomà, C. (2020). Digital social innovation and urban space: A critical geography agenda. Urban Planning, 5(4), 8-19.

Certomà, C., Rizzi, F., \& Corsini, F. (2015). Crowdsourcing urban sustainability: Data, people and technologies in participatory governance. Futures, 74, 93-106.

Coleman, G. (2015). Hacker, hoaxer, whistleblower, spy: The story of Anonymous. London: Verso.

de Cindio, F., \& Aurigi, A. (2008). The augmented urban space. London: Routledge.

Devlin, C. (2020). Digital social innovation and the adoption of \#PlanTech: The case of Coventry city council. Urban Planning, 5(4), 59-67.

Dyer, M., Dyer, R., Weng, M-H., Wu, S., Grey, T., Gleeson, R., \& Ferrari, T. G. (2019). Framework for soft and hard city infrastructures. Proceedings of the Institution of Civil Engineers-Urban Design and Planning, 172(6), 219-227.

Dyer, M., Gleeson, D., Ögmundadottir, H., Ballantyne, A. G., \& Bolving, K. (2017). Awareness, communication and visualisation. In M. E. Goodsite \& S. Juhola (Eds.), Green defense technology (pp. 269-286). Dordrecht: Springer.

Dyer, M., Weng, M-H., Wu, S., Ferrari, T. G., \& Dyer, R. (2020). Urban narrative: Computational linguistic interpretation of large format public participation for urban infrastructure. Urban Planning, 5(4), 20-32.

Ersoy, A., \& van Bueren, E. (2020). Challenges of urban living labs towards the future of local innovation. Urban Planning, 5(4), 89-100.

Fixmystreet. (2020). Report, view, or discuss local problems. Fixmystreet. Retrieved at https://www. fixmystreet.com

Flynn, D. J., Nyhan, B., \& Reifler, J. (2017). The nature and origins of misperceptions: Understanding false and unsupported beliefs about politics. Political Psychology, 38(S1), 127-150.

Gairola, R. K., \& Roth, M. (2019). Cyber zones: Digital spatialities and material realities across Asia. Asiascape: Digital Asia, 6(1/2), 4-16.

Gleeson, D., Dyer, M., \& Grey, T. (2017). Framework for collaborative urbanism. In C. Certomà, M. Dyer, L. Pocatilu, \& F. Rizzi (Eds.), Citizen empowerment and innovation in the data-rich city (pp. 19-30). Cham: Springer.

Graham, M., Zook, M., \& Boulton, A. (2013). Augmented reality in the urban environment. Transactions of the IBG, 38, 464-479.

Grossberndt, S., Schneider, P., Liu, H-Y., Fredriksen, M. F., Castell, N., Syropoulou, P., \& Bartoňová, A. (2020). Public perception of urban air quality using volunteered geographic information services. Urban Planning, 5(4), 45-58.

Guifi. (2020). Xarxa de telecomunicacions de comuns oberta, lliure i neutral [Commons telecommunica- 
tions network open, free and neutral]. Guifi. Retrieved from https://guifi.net

Herzog, S. M., \& Hertwig, R. (2011). The wisdom of ignorant crowds: Predicting sport outcomes by mere recognition. Judgment and Decision Making, 6, 58-72.

Howaldt, J., \& Schwarz, M. (2016). Social innovation and its relationship to social change: Verifying existing social theories in reference to social innovation and its relationship to social change. Brussels: European Commission.

Ind.ie. (2020). Homepage. Indie.ie. Retrieved from https://ind.ie

Lanier, J. (2006). Digital Maoism: The hazards of the new online collectivism. Edge. Retrieved from https://www.edge.org/conversation/jaron_lanierdigital-maoism-the-hazards-of-the-new-onlinecollectivism

Lawrence, T. B., Dover, G., \& Gallagher, B. (2014). Managing social innovation. In M. Dodgson, D. M. Gann, \& N. Phillips (Eds.), The Oxford handbook of innovation management (pp. 316-334). Oxford: Oxford University Press.

Leyshon, M., \& Rogers, M. (2020). Designing for inclusivity: Platforms of protest and participation. Urban Planning, 5(4), 33-44.

Lleialtat. (2020). Pla de Sobirania Tecnològica per l'acció comunitària [Technology for community action]. Lleialtec. Retrieved from https://tec.lleialtat.cat

Maglavera, T., Niavis, H., Moutsinas, G., Passani, A., \& De Rosa, S. (2019). D5.2: Digital transformation for a better society-White paper (Grant Agreement No. 687686). Brussels: ChiC, European Commission. Retrieved from https://capssi.eu/wp-content/uploads/ ChiC_D5.2_Digital_Transformation_for_a_better_ society-whitepaper.pdf

Millard, J., \& Carpenter, G. (2014). Digital technology in social innovation. Brussels: European Commission.

Moore, M., Riddell, D., \& Vocisano, D. (2015). Scaling out, scaling up, scaling deep: Strategies of non-profits in advancing systemic social innovation. The Journal of Corporate Citizenship, 2015(58), 67-84. Retrieved from http://www.jstor.org/stable/jcorpciti.58.67

Mosquera, J. (2020). Fragnebenan: Empowering neighbourhood life with a local social network. Cooperative City. Retrieved from https://cooperativecity.org/ 2018/07/21/fragnebenan-local-social-network Mossberger, K., Tolbert, C. J., \& McNeal, R. S. (2007). Dig- ital citizenship: The Internet, society, and participation. Cambridge, MA: MIT Press.

Moulaert, F., MacCallum, D., Mehmood, A., \& Hamdouch, A. (2013). International handbook of social innovation. Cheltenham: Edward Elgar.

Nesta. (2020). ShareTown. Nesta. Retrieved from https://www.nesta.org.uk/data-visualisation-andinteractive/sharetown

Parayil, G. (2005). Information capitalism. New York, NY: Springer.

Passani, A., Spagnoli, F., Bellini, F., Prampolini, A., \& Firus, K. (2016). Collective awareness platform for sustainability and social innovation (CAPS). In C. Rossignoli, M. Gatti, \& R. Agrifoglio (Eds.), Organizational innovation and change: Lecture notes in information systems and organization (Vol. 13; pp. 103-114). Cham: Springer.

Prahalad, C. K., \& Ramaswamy, V. (2004). Co-creation experiences: The next practice in value creation. Journal of Interactive Marketing, 18(3), 5-14.

Smart Citizen. (2020). Smart citizen kit. Wikifactory. Retrieved from https://projects.fablabs.io/+fablabbcn/ smart-citizen-kit

Speak. (2020). Learn a language and meet people online. Speak. Retrieved from www.speak.social

Spicknall, S. (2018). A Chicagoan's introduction to civic tech: 2018. Microsoft. Retrieved from https://blogs.microsoft.com/chicago/2018/01/ 19/chicagoans-introduction-civic-tech-2018/

TEPSIE. (2014). Social innovation theory and research: A summary of the findings from TEPSIE. Brussels: European Commission.

Thompson, M. (2018). Playing with the rules of the game: Social innovation for urban transformation. International Journal of Urban and Regional Research, 29(2), 375-388.

Westley, F., Antadze, N., Riddell, D. J., Robinson, K., \& Geobey, S. (2014). Five configurations for scaling up social innovation: Case examples of nonprofit organizations from Canada. The Journal of Applied Behavioral Science, 50(3), 234-260. https://doi.org/ 10.1177/0021886314532945

Zerrer, N., \& Sept, A. (2020). Smart villagers as actors of digital social innovation in rural areas. Urban Planning, 5(4), 78-88.

Zuboff, S. (2019). The age of surveillance capitalism: The fight for a human future at the new frontier of power. New York, NY: Public Affairs.

\section{About the Authors}

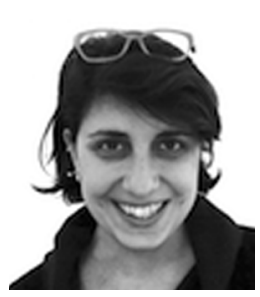

Chiara Certomà is an Assistant Professor in Political-Economic Geography at the University of Turin, an Affiliate Researcher at Ghent University, and an Honorary Research Associate at The University of Waikato. Her interests focus on innovative modes of urban governance and planning in the face of pressing environmental challenges and the digital turn. Information about her research projects and publications can be found at https://crowdusg.net 


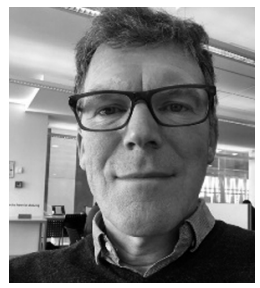

Mark Dyer is Dean of Engineering at University of Waikato, New Zealand. Previously he held the McNamara Chair in Construction Innovation at Trinity College Dublin, from 2008 to 2019, where he established TrinityHaus as a centre for research and innovation for people, cities, and infrastructure. His earlier professional experience in the 1980s and 1990s involved the design and construction of major infrastructure projects in Europe, Africa, and Asia.

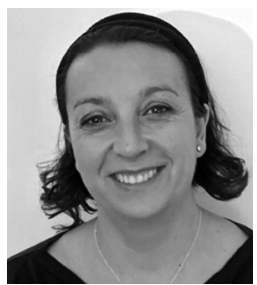

Antonella Passani is Head of Research and Partner at T6 Ecosystems, a research and consultancy company based in Rome, Italy. As a Social Scientist she has more than 17 years of experience in large, interdisciplinary innovation projects supporting the development and the analysis of socio-technical solutions for social and environmental challenges. Her main research topics are the socio-economic impacts of innovation process, co-design and participatory processes for innovation, digital social innovation, and, more recently, citizens science. 